\title{
Circulating levels of homocysteine in preeclamptic women
}

\author{
Khosrowbeygi A, Ahmadvand $\mathrm{H}$ \\ Department of Biochemistry, School of Medicine, Lorestan University of Medical Sciences, Khorramabad, Iran.
}

\begin{abstract}
It has been hypothesized that maternal hyperhomocysteinemia to be associated with preeclampsia. The aims of the present study were to examine maternal serum levels of total homocysteine in preeclamptic women and its association with the severity of the disease. The study population consisted of 30 preeclamptic patients and 30 matched healthy pregnant women. Serum levels of total homocysteine were assessed using enzyme immunoassay method. Maternal serum levels of total homocysteine were significantly higher in preeclamptic group than in normal pregnant women. Women with severe preeclampsia had higher serum levels of total homocysteine than mild preeclamptic patients. Levels of total homocysteine correlated positively with systolic blood pressure values in preeclamptic women. In summary, maternal serum levels of total homocysteine were increased in preeclamptic women and hyperhomocysteinemia was associated with severity of preeclampsia.
\end{abstract}

\section{Introduction}

Preeclampsia, a pregnancy specific syndrome, is a major cause of maternal and perinatal morbidity and mortality with a worldwide incidence of 5-8\% of all pregnancies ${ }^{1,2}$. Preeclampsia is characterized by the onset of hypertension and proteinuria after 20 weeks of gestation in a previously normotensive pregnant woman ${ }^{1,3}$. Despite a fairly high incidence, the underlying etiology of preeclampsia is still incomplete $^{1,2}$. There are many theories about the etiology and pathogenesis of preeclampsia including endothelial dysfunction, inflammation and angiogenesis ${ }^{1,3}$.

Homocysteine, a sulfur containing amino acid, is involved in processes such as lipid peroxidation and oxidative stress ${ }^{1,4}$. Hyperhomocysteinemia is a risk factor for endothelial dysfunction and vascular disease such as atherosclerosis. It has been hypothesized that maternal hyperhomocysteinemia to be associated with a number of placentamediated diseases such as preeclampsia ${ }^{4-6}$.

There are some conflicting findings of maternal circulating levels of homocysteine in preeclamptic women. Large bodies of studies report hyperhomocysteinemia in preeclamptic women compared with normal pregnant women ${ }^{4-13}$. However, some studies have shown that there is no difference in circulating concentrations of homocysteine between mild preeclampsia and healthy pregnant women ${ }^{4,11}$, and between mild and severe preeclampsia ${ }^{4,14}$. Therefore, a crosssectional study was designed to examine maternal serum levels of homocysteine in preeclamptic women and its association with the severity of preeclamsia.

\section{Materials and Methods}

A cross-sectional study was designed. The study was approved by Institutional Ethical Review Board, and informed consent was obtained from each pregnant woman enrolled in this study. Sixty pregnant women were included in the present study. Of these 30 women were preeclamptic patients and 30 age, gestational week, and body mass index (BMI) - matched were as normal group. Preeclampsia was defined as blood pressure equal to or higher than $140 / 90 \mathrm{mmHg}$ with proteinuria of either higher than $100 \mathrm{mg} / \mathrm{dl}$ by urine analysis or higher than $300 \mathrm{mg}$ in a 24-h urine collection. Severe preeclampsia was defined as blood pressure equal to or higher than 160/110 $\mathrm{mmHg}$. Exclusion criteria were smoking, multiple gestation, diabetes mellitus, chronic hypertension, heart failure, renal disease, inflammatory or infective disorders, infectious disease, and treatment with antifolate drugs ${ }^{4}$. All of the samples were being supplemented with vitamins B and folate during pregnancy. Blood samples were collected from preeclamptic patients at the time of acceptance to the hospital shortly after the preeclampsia diagnosis was confirmed. Serum samples were stored at $-70^{\circ} \mathrm{C}$ until examination.

Total homocysteine levels were measured by enzyme immunoassay (EIA) method. We used commercially available EIA method (Axis Homocysteine EIA, Axis-Shield Diagnostic Ltd, 
United Kingdom). The procedure for the EIA was according to the instructions provided by the manufacturer. The sample volume that used was 25 $\mu \mathrm{l}$. Absorbance was measured at a wavelength of $450 \mathrm{~nm}$ using enzyme-linked immunosorbent assay (ELISA) reader (STAT FAX 2100, USA). The concentration of total homocysteine was calculated from a semi-logarithmic standard curve of standard samples vs. absorbance at $450 \mathrm{~nm}$ and was presented as $\mu \mathrm{mol} / \mathrm{l}$. The intra-assay coefficient of variation was $<10 \%$. The sensitivity of the assay was $2.0 \mu \mathrm{mol} / 1$.

Based on a literature review, using an $\alpha$ value of 0.05 and a $\beta$ value of 0.2 ( $80 \%$ power), the minimum sample size required was calculated 30 samples per group. Differences between patients and normal groups were assessed using unpaired Student's $t$ test. Coefficients of correlation were calculated using Pearson's correlation analysis. All hypothesis tests were two-tailed with statistical significance assessed at the $p$-value $<0.05$ level with $95 \%$ confidence intervals. The data are expressed as the Mean \pm SEM. Statistical computations were calculated using SPSS 11.5 for windows software.

\section{Results}

Characteristics of normal pregnant women and preeclamptic patients are shown in Table-I. There were no significant differences in age, gestational age, BMI before pregnancy, and third trimester BMI between the preeclamptic and control groups. Women with preeclampsia had higher mean systolic and diastolic blood pressures than the normal pregnant women.

Maternal serum levels of total homocysteine were significantly higher in preeclamptic group than in normal pregnant women (Table-I). Patients were then stratified to mild $(n=17)$ and severe $(n=13)$ preeclampsia. Women with severe preeclampsia had higher serum levels of total homocysteine than mild preeclamptic patients $(17.40 \pm 2.7$ vs $11.49 \pm 1.19 \mu \mathrm{mol} / 1, p=0.000)$ and normal pregnant women $(17.40 \pm 2.7$ vs $6.38 \pm 0.3 \mu \mathrm{mol} / 1, p=0.000)$. Serum levels of total homocysteine were significantly higher in women with mild preeclampsia than those in normal pregnant women (11.49 \pm 1.19 vs $6.38 \pm 0.3 \mu \mathrm{mol} / 1, p=0.000)$.

Levels of total homocysteine correlated positively with systolic blood pressure values in preeclamptic women ( $\mathrm{r}=0.44, p=0.01$ ) (Fig. 1). When both normal pregnant women and preeclamptic patients were pooled, levels of total homocysteine showed a significant correlation with both systolic $(\mathrm{r}=0.65$, $p=0.000$ ) (Fig. 2) and diastolic ( $\mathrm{r}=0.34, p=0.007)$ (Fig. 3) blood pressures.
Table I: Characteristics of Normal Pregnant and Preeclamtic Women

\begin{tabular}{lccc}
\hline Parameter & $\begin{array}{c}\text { Normal } \\
\text { pregnancy } \\
(\mathrm{n}=30)\end{array}$ & $\begin{array}{c}\text { Preeclampsia } \\
(\mathrm{n}=30)\end{array}$ & $p$ \\
\hline Age (years) & $31.07 \pm 0.35$ & $32.27 \pm 0.69$ & 0.2 \\
Gestational age (weeks) & $39.10 \pm 0.23$ & $38.50 \pm 0.24$ & 0.09 \\
BMI before pregnancy $\left(\mathrm{kg} / \mathrm{m}^{2}\right)$ & $21.95 \pm 0.50$ & $23.65 \pm 0.75$ & 0.08 \\
Third trimester BMI $\left(\mathrm{kg} / \mathrm{m}^{2}\right)$ & $26.23 \pm 0.51$ & $27.88 \pm 0.78$ & 0.1 \\
Systolic blood pressure $(\mathrm{mm} \mathrm{Hg})$ & $109.00 \pm 1.11$ & $150.67 \pm 1.91$ & 0.001 \\
Diastolic blood pressure $(\mathrm{mm} \mathrm{Hg})$ & $66.33 \pm 1.31$ & $95.67 \pm 2.23$ & 0.001 \\
Homocysteine $(\mu \mathrm{mol} / \mathrm{l})$ & $6.38 \pm 0.3$ & $14.05 \pm 1.43$ & 0.00 \\
\hline
\end{tabular}

Results are presented as mean \pm SEM. BMI=Body Mass Index

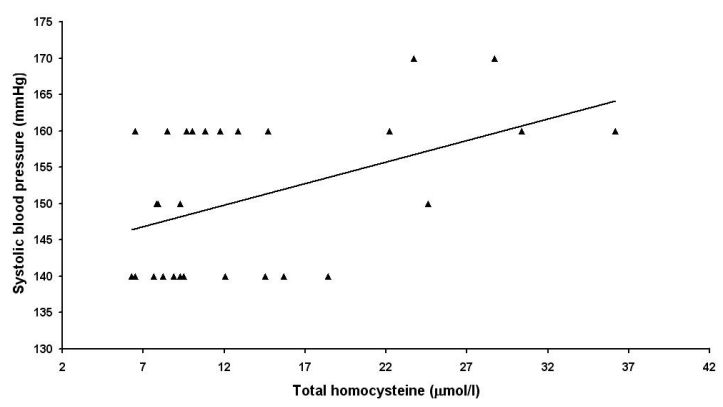

Fig. 1: Correlation between serum levels of total homocysteine and systolic blood pressure in the patients with preeclampsia $(n=30)(r=$ $0.44, p=0.01$ )

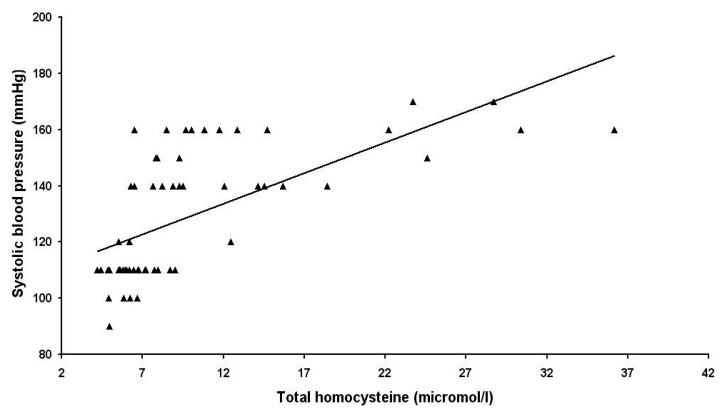

Fig. 2: Correlation between serum levels of total homocysteine and systolic blood pressure in entire 30 preeclamptic and 30 normal pregnant women $(\mathrm{r}=0.65, p=0.000)$.

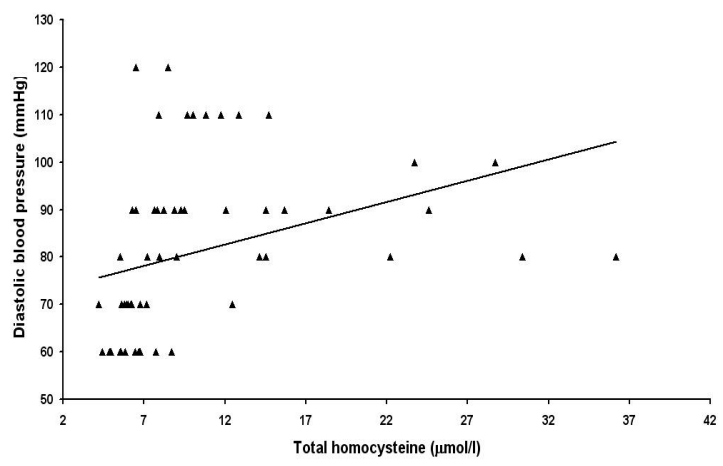

Fig. 3: Correlation between serum levels of total homocysteine and diastolic blood pressure in entire 30 preeclamptic and 30 normal pregnant women $(\mathrm{r}=0.34, p=0.007)$.

\section{Discussion}

The most relevant findings of this study were (i) a significant increase in maternal serum levels of total homocysteine in both mild and severe 
preeclamptic subjects than those in normal pregnant women, and (ii) a significant positive correlation between serum levels of total homocysteine and systolic blood pressure in preeclamptic patients.

Our findings were in line with the studies reporting the increased maternal serum levels of homocysteine in preeclamptic patients compared with normal pregnant women ${ }^{4-13}$. However, our data are not agreed with Zeeman et $\mathrm{al}^{15}$, study that showed there is no significant difference in maternal serum levels of homocysteine between preeclampsia and normal pregnancy.

Our results are agreed with some previous studies that show increasing of maternal serum levels of homocysteine in severe preeclampsia compared with mild preeclampsia ${ }^{8,11}$. However, our finding was not agreed with other studies reporting there is no significant difference in circulating concentration of homocysteine between severe and mild preeclamptic women ${ }^{4,14}$.

Our data confirmed the results obtained by Gurbuz et $\mathrm{al}^{8}$, study who observed that circulating levels of homocysteine are significantly higher in mild preeclamptic patients than those in normal pregnant women. On the contrary, Ingec et $\mathrm{al}^{4}$ and Hasanzadeh et $\mathrm{al}^{13}$ found that there is not any significant differences in circulating levels of homocysteine between mild preeclamptic and normal pregnant women.

Our data are agreed with the previous study that shows association between circulating levels of homocysteine and blood pressure in preeclamptic patients ${ }^{4}$. In contrast, Lopez et $\mathrm{al}^{7}$ have not observed this relationship.

There are contradictory results of the potential of homocysteine as a marker for subsequent preeclampsia. Some studies showed that hyperhomocysteinemia in early pregnancy can increase the risk of developing of preeclampsia $^{7,16,17}$. In contrast, other studies detected no differences in midtrimester maternal circulating level of homocysteine between women who developed preeclampsia and normal pregnant women $^{15,18-20}$.

In uncomplicated pregnancies maternal circulating level of homocysteine is decreased, probably resulting from hemodilution, increased glomerular filtration rate, hormonal changed, increased uptake of the amino acid by fetus, and increasing in enzymatic activity related to homocysteine metabolism ${ }^{21}$.

Vitamins B6, B12 and folate play central roles in homocysteine metabolism. If $\mathrm{B}$ vitamins are not present in adequate amounts to support these metabolic changes, then the natural decrease of homocysteine might not occur and hyperhomocysteinemia can develop. Vitamin B deficiencies might thus confer a greater risk of preeclampsia on the mother. Hyperhomocysteinemia caused by the methylenetetrahydrofolate reductase C677T mutation, can be corrected with folic acid administration ${ }^{6}$. There are some conflicting findings about the association of hyperhomocysteinemia and maternal circulating levels of $\mathrm{B}$ vitamins in preeclamptic women. $\mathrm{D}^{\prime}$ Anna et $\mathrm{al}^{22}$, report suggests that deficiencies in $B$ vitamins and folate are associated with an increased risk of preeclampsia. An interventional trial has demonstrated that folate supplementation in the second trimester of pregnancy significantly reduces both serum homocysteine levels and the risk of preeclampsia ${ }^{23}$. Markedos et $\mathrm{al}^{6}$, Braekke et $\mathrm{al}^{10}$ and Guven et $\mathrm{al}^{24}$, studies showed that maternal circulating concentrations of vitamins B12 and folic acid are not significantly different in hyperhomocysteinemic preeclamtic group compared with normal pregnant women. Lopez et $\mathrm{al}^{7}$ found that the levels of homocysteine and folate are increased in preeclampsia, but values of vitamin B12 are not changed compared with normal pregnancy. In the present study, all of the samples were being supplemented with vitamins B and folate during pregnancy. Therefore, the hyperhomocysteinemia observed in the preeclamptic women might not be due to the vitamins deficiency.

In summary, the present study has shown an increased in maternal serum levels of total homocysteine in both mild and severe preeclampsia compared with normal pregnancy, and association of total homocysteine concentrations with the severity of preeclampsia.

\section{Acknowledgment}

This research was supported by a grant from Lorestan University of Medical Sciences. The author thanks Dr. N. Lorzadeh for providing the samples and Mr. M. Birjandi for data analysis.

\section{References}

1. Baumann MU, Bersinger NA, Surbek DV. Serum markers for predicting pre-eclampsia. Mol Aspects Med 2007; 28:227-44.

2. Shenoy V, Kanasaki K, Kalluri R. Pre-eclampsia: connecting angiogenic and metabolic pathways. Trends Endocrinol Metab 2010 In press.

3. Mohaupt M. Molecular aspects of preeclampsia. Mol Aspects Med 2007; 28: 169-91. 
4. Ingec M, Borekci B, Kadanali S. Elevated plasma homocysteine concentrations in severe preeclampsia and eclampsia. Tohoku J Exp Med 2005; 206: 225-31.

5. Mao D, Che J, Li K, Han S, Yue Q, Zhu L, et al. Association of homocysteine, asymmetric dimethylarginine, and nitric oxide with preeclampsia. Arch Gynecol Obstet 2009 In press.

6. Makedos G, Papanicolaou A, Hitoglou A, Kalogiannidis I, Makedos A, Vrazioti V, et al. Homocysteine, folic acid and B12 serum levels in pregnancy complicated with preeclampsia. Arch Gynecol Obstet 2007; 275: 121-4.

7. López-Quesada E, Vilaseca MA, Lailla JM. Plasma total homocysteine in uncomplicated pregnancy and in preeclampsia. Eur J Obstet Gynecol Reprod Biol 2003; 108: 45-9.

8. Gurbuz A, Karateke A, Mengulluoglu M. Elevated plasma homocysteine levels in preeclampsia and eclampsia. Int J Gynaecol Obstet 2004; 87: 165-6.

9. Harma M, Harma M, Kocyigit A. Correlation between maternal plasma homocysteine and zinc levels in preeclamptic women. Biol Trace Elem Res 2005; 104: 97-105.

10. Braekke K, Ueland PM, Harsem NK, Karlsen A, Blomhoff R, Staff AC. Homocysteine, cysteine, and related metabolites in maternal and fetal plasma in preeclampsia. Pediatr Res 2007; 62: 319-24.

11. Hasanzadeh M, Ayatollahi H, Farzadnia M, Ayati S, Khoob MK. Elevated plasma total homocysteine in preeclampsia. Saudi Med J 2008; 29: 875-8.

12. Hoque MM, Bulbul T, Mahal M, Islam NA, Ferdausi M. Serum homocysteine in pre-eclampsia and eclampsia. Bangladesh Med Res Counc Bull 2008; 34 : 16-20.

13. Singh U, Gupta HP, Singh RK, Shukla M, Singh R, Mehrotra SS, et al. A study of changes in homocysteine levels during normal pregnancy and preeclampsia. J Indian Med Assoc 2008; 106: 503-5.

14. Atis A, Aydin Y, Başol E, Göker N. Troponin I and homocysteine levels in mild and severe preeclampsia. Clin Exp Obstet Gynecol 2010; 37: 21-3.

15. Zeeman GG, Alexander JM, McIntire DD, Devaraj S, Leveno KJ. Homocysteine plasma concentration levels for the prediction of preeclampsia in women with chronic hypertension. Am J Obstet Gynecol 2003; 189: 574-6.

16. Cotter AM, Molloy AM, Scott JM, Daly SF. Elevated plasma homocysteine in early pregnancy: a risk factor for the development of nonsevere preeclampsia. Am J Obstet Gynecol 2003; 189: 391-4.

17. Dodds L, Fell DB, Dooley KC, Armson BA, Allen AC, Nassar BA, et al. Effect of homocysteine concentration in early pregnancy on gestational hypertensive disorders and other pregnancy outcomes. Clin Chem 2008; 54: 326-34.

18. D'Anna R, Baviera G, Corrado F, Ientile R, Granese D, Stella NC. Plasma homocysteine in early and late pregnancies complicated with preeclampsia and isolated intrauterine growth restriction. Acta Obstet Gynecol Scand 2004; 83: 155-8.

19. Yu CK, Lakasing L, Papageorghiou AT, Spencer K, Nicolaides KH. Uterine artery Doppler and midtrimester maternal plasma homocysteine in subsequent pre-eclampsia. J Matern Fetal Neonatal Med 2004; 16: 134-9.

20. Onalan R, Onalan G, Gunenc Z, Karabulut E. Combining 2nd-trimester maternal serum homocysteine levels and uterine artery Doppler for prediction of preeclampsia and isolated intrauterine growth restriction. Gynecol Obstet Invest 2006; 61: 142-8.

21. Dasarathy J, Gruca LL, Bennett C, Parimi PS, Duenas $\mathrm{C}$, Marczewski $\mathrm{S}$ et al. Methionine metabolism in human pregnancy. Am J Clin Nutr 2010; 91: 357-65.

22. Herrmann W, Isber S, Obeid R, Herrmann M, Jouma M.Concentrations of homocysteine, related metabolites and asymmetric dimethylarginine in preeclamptic women with poor nutritional status. Clin Chem Lab Med 2005; 43: 1139-46.

23. Wen SW, Chen XK, Rodger M, White RR, Yang Q, Smith GN, et al. Folic acid supplementation in early second trimester and the risk of preeclampsia. Am J Obstet Gynecol 2008; 198: 45.e1-7.

24. Guven MA, Coskun A, Ertas IE, Aral M, Zencirci B, Oksuz H. Association of maternal serum CRP, IL-6, TNF-alpha, homocysteine, folic acid and vitamin B 12 levels with the severity of preeclampsia and fetal birth weight. Hypertens Pregnancy 2009; 28: 190-200. 